\title{
Autonomia e independência: percepção de adolescentes com deficiência visual e de seus cuidadores
}

\section{Autonomy and independence: the perception of teens with visual impairment and their caregivers}

\author{
Jhenifer Geisa Burnagui ${ }^{1}$, Mariana Peres da Rosa ${ }^{2}$, \\ Gabriela Cordeiro Corrêa do Nascimento ${ }^{3}$
}

http://dx.doi.org/10.11606/issn.2238-6149.v27i1p21-28

Burnagui JG, Rosa MP, Nascimento GCC. Autonomia e independência: percepção de adolescentes com deficiência visual e de seus cuidadores Autonomy and independence: the perception of teens with visual impairment and their caregivers. Rev Ter Ocup Univ São Paulo. 2016 jan.-abr.;27(1):21-8

RESUMO: A adolescência é uma fase de vida marcada por transições, pela construção da identidade e pela conquista de autonomia e independência, que para o adolescente com deficiência visual esta etapa pode ser marcada por maiores dificuldades na aquisição destas habilidades. Destaca-se, ainda, que a família possui papel central neste contexto. Diante disso, buscou-se analisar se há diferenças entre as percepções de adolescentes com deficiência visual e de seus cuidadores quanto às vivências de autonomia e independência desses indivíduos, sendo necessário identificar a compreensão dos participantes quanto aos termos autonomia e independência. A fim de atingir os objetivos, utilizou-se a metodologia de pesquisa qualitativa exploratória e descritiva. Obtiveram-se dissonâncias entre os entendimentos dos termos, porém, após a explicação dos conceitos adotados para este estudo, todos os participantes descreveram os adolescentes como autônomos e independentes e não existiram discrepâncias quanto às percepções das vivências dos mesmos. Contudo, considerase necessária a realização de mais pesquisas nesta área, visto a relevância da conceituação dos termos autonomia e independência para a Terapia Ocupacional e a escassez de publicações encontradas.

DESCRITORES: Terapia ocupacional; Pessoas com deficiência visual; Adolescente; Autonomia pessoal.
Burnagui JG, Rosa MP, Nascimento GCC. Autonomy and independence: the perception of teens with visual impairment and their caregivers. Rev Ter Ocup Univ São Paulo. 2016 Jan.-Apr.;27(1):21-8

ABSTRACT: Adolescence is a life stage marked by transitions, by building their identity and achievement of autonomy and independence, for the adolescent with visual impairment this stage of life can be marked by greater difficulties in acquiring these skills. Highlighting the central role of the family in this context. Of this before, attempted to examine whether there are differences between the perceptions of adolescents with visual impairment and their caregivers about the experiences of self-autonomy and independence of these individuals, being necessary to identify the comprehension of the participants on the terms autonomy and independence. In order to reach the goals, it was used the qualitative exploratory and descriptive research methodology. Was obtained dissonances between the understandings of terms, however, after the explanation of the concepts adopted for this study, all participants described the adolescents as autonomous and independent and there were no discrepancies in the perceptions of the experiences of them. However, it is considered necessary to carry out more research in this area, given the relevance of the concept of the terms autonomy and independence for Occupational Therapy and the scarcity of publications found.

KEYWORDS: Occupational therapy; Visually impaired persons; Adolescent; Personal autonomy.

Este estudo constitui-se de um recorte do projeto de pesquisa e extensão intitulado "Atenção terapêutica ocupacional a pessoas com deficiência visual nas diferentes etapas do ciclo de vida" do Laboratório de Desenvolvimento e Contextos Escolares do departamento de Terapia Ocupacional da Universidade Federal do Paraná (UFPR), aprovado pelo Comitê de Ética em Pesquisa em Seres Humanos do Setor de Ciências da Saúde (CEP/SD) da UFPR, sob o parecer de número 925.702, e CAAE nº. 26208713.1.0000.0102.

1. Acadêmicas do curso de Terapia Ocupacional da Universidade Federal do Paraná. E-mail: jhenifergb@gmail.com

2. Acadêmicas do curso de Terapia Ocupacional da Universidade Federal do Paraná. E-mail: maarip.rosa@gmail.com

3. Mestre em Saúde, Interdisciplinaridade e Reabilitação pela UNICAMP. Professora do Departamento de Terapia Ocupacional da Universidade Federal do Paraná

Endereço para correspondência: Universidade Federal do Paraná. Campus Botânico, Bloco Didático II, Departamento de Terapia Ocupacional. Av. Lothário Meissner, 632. Bairro Jardim Botânico, Curitiba, PR. CEP: 80210-170. E-mail: gabriela.correa@ufpr.br 


\section{INTRODUÇÃO}

$\mathrm{A}$ visão se constitui como uma das principais vias para a percepção e construção de mundo, logo, a deficiência visual representa uma barreira para esta construção, e, em decorrência disso, uma limitação na aquisição de habilidades necessárias para a realização de atividades do cotidiano ${ }^{1,2}$.

A deficiência visual subdivide-se em dois grupos: cegueira e baixa visão. As pessoas com cegueira são aquelas que, por terem pouca ou nenhuma capacidade de visão residual, utilizam-se principalmente de recursos substitutivos da visão para a realização das atividades de vida diária, tais como a bengala, comunicação escrita através do alfabeto Braille, softwares ledores de tela, entre outros ${ }^{3}$.

A baixa visão, que engloba um grupo maior de pessoas do que a cegueira, é considerada variável de complexo controle, pois existem diversos graus de acuidade visual $^{3,4}$. Além disso, compreende-se que o resíduo visual existente é subjetivo, então, a habilidade de usá-lo depende, além da acuidade visual ou da patologia, da eficácia do uso da visão, sendo que esta pode ser melhorada com o uso de recursos ópticos e/ou não ópticos ${ }^{3,5}$.

Neste sentido, destacando que a adolescência marca a transição entre a infância e a fase adulta, e é constituída por um complexo período de crescimento e desenvolvimento biopsicossocial ${ }^{6}$, entende-se que nesta fase da vida a aquisição de habilidades pode ser singularmente afetada pela deficiência visual.

No Brasil, o Estatuto da Criança e do Adolescente (ECA), considera adolescente, aquele que tem entre doze e dezoito anos de idade 7 . Esta é uma etapa da vida permeada por alguns tabus como a sexualidade, dilemas pela escolha profissional e a luta por uma maior independência ${ }^{8}$.

É na adolescência que ocorrem diversos conflitos, são redefinidos valores, atitudes, percepções de autonomia e independência, motivações e desinteresses. Nesta fase há uma reconfiguração de identidade, uma nova construção de si, que tem a deficiência visual como fator constituinte e envolve, além das mudanças fisiológicas e do despertar da sexualidade, as relações familiares e sociais ${ }^{9-11}$.

Destaca-se o papel central da família no processo de desenvolvimento do adolescente. No âmbito familiar são constituídos valores e crenças, são vivenciadas interações cotidianas e relações que permitem o desenvolvimento de competências sociais, dentre elas autonomia e independência ${ }^{12,13}$.

Cuidadores próximos de adolescentes com deficiência visual, geralmente pais e/ou avós, por vezes têm em si despertados sentimentos de superproteção e cuidado excessivo, podendo, dessa forma, interferir nos processos de obtenção de autonomia e independência ${ }^{14}$.

A definição de autonomia e independência é empregada de maneiras distintas a partir do referencial que se utiliza. Assim, como parâmetro denotativo, considerouse as definições dos termos "autonomia" e "independência" existentes no minidicionário Houaiss da língua portuguesa ${ }^{15}$. Neste, a palavra autonomia é definida como "capacidade de governar a si próprio", sendo considerado como autônomo o indivíduo "capaz de determinar as próprias normas de conduta, sem imposições" (p.78) ${ }^{15}$. O termo independência é definido como o "estado daquele que goza de autonomia, de liberdade com relação a alguém ou alguma coisa", enquanto, por independente, é considerado o indivíduo "que não depende de nada nem de ninguém" (p.411)

Campos e Campos ${ }^{16}$ entendem por autonomia a capacidade individual de se autogerir, ou seja, agir por si mesmo sem existir interferência de outras pessoas. Apontam que o conceito refere-se a algo que não compete à sociedade, sendo a possibilidade da expressão individual ${ }^{16}$.

Referente à conceituação do termo independência, o manual de orientação funcional para a utilização da Medida de Independência Funcional (MIF) apresenta como pessoa independente aquela que "não necessita de ajuda de alguém para desenvolver a atividade (sem ajudante)" (p.2) ${ }^{17}$.

Buscando compreender a conceituação dos termos autonomia e independência em referenciais específicos da Terapia Ocupacional, encontrou-se a conceituação do termo autonomia descrita como a capacidade de o sujeito agir a partir de suas próprias regras, valores e crenças, sem controle ou interferência de outras pessoas ${ }^{18}$.

A conceituação de independência encontrada foi descrita com base em diferentes modelos de incapacidade, considerando que os significados dos termos podem modificar-se dependendo do modelo adotado ${ }^{19}$.

Assim, para Hammel et al. ${ }^{19}$, independência, quando conceituada pelo Modelo Médico, refere-se à "capacidade física, cognitiva e mental do indivíduo para agir e tomar decisões". Tomando como base o Modelo de Reabilitação, independência diz respeito às capacidades física e cognitiva da pessoa em realizar atividades sem auxílio de outros e de forma segura, em tempo adequado. Para o Modelo de Grupo Minoritário/Social, independência significa ser capaz de exercer sua liberdade no sentido de poder ir e vir e, também, ter domínio sobre sua vida cotidiana, bem como poder sustentá-la ${ }^{19}$.

A partir das conceituações encontradas, adotou-se para esta pesquisa,autonomia como sendo a competência 
de cada sujeito de agir de acordo com sua própria escolha e decisão, e independência como a capacidade de desempenhar atividades e papéis sociais sem auxílio de outrem.

Frente ao exposto, o objetivo geral desta pesquisa foi identificar se existem diferenças na percepção de adolescentes com deficiência visual e seus cuidadores quanto às vivências e experiências de autonomia e independência desses indivíduos. Para tanto foi necessário identificar as diferentes concepções em relação aos conceitos de autonomia e independência entre adolescentes com deficiência visual e seus cuidadores.

\section{PROCEDIMENTOS METODOLÓGICOS}

O estudo trata-se de um recorte do projeto de pesquisa e extensão intitulado "Atenção terapêutica ocupacional a pessoas com deficiência visual nas diferentes etapas do ciclo de vida" do Laboratório de Desenvolvimento e Contextos Escolares do departamento de Terapia Ocupacional da Universidade Federal do Paraná (UFPR), aprovado pelo Comitê de Ética em Pesquisa em Seres Humanos do Setor de Ciências da Saúde (CEP/SD) da UFPR, sob o parecer de número 925.702, e CAAE $n^{\circ}$. 26208713.1.0000.0102.

Optou-se pela pesquisa qualitativa, de cunho exploratório-descritivo, que busca descrever características de determinada população ou fenômeno, utilizando-se de instrumentos específicos para coleta de dados como, por exemplo, entrevistas ${ }^{20}$.

A população pesquisada foi de adolescentes com deficiência visual vinculados a uma instituição especializada, parceira do projeto, situada na cidade de Curitiba - PR, direcionada à habilitação e reabilitação de pessoas com deficiência visual, e seus cuidadores mais próximos.

Adotou-se como critérios de inclusão os adolescentes com deficiência visual (cegueira ou baixa visão), de ambos os sexos, com idades entre doze e dezoito anos. Quanto aos cuidadores, estabeleceu-se como critérios de inclusão que estes fossem próximos aos adolescentes, fazendo parte de sua rotina; tivessem conhecimento de suas vivências cotidianas; mais do que dezoito anos; e de ambos os sexos.

As finalidades do estudo foram esclarecidas e foi assegurado às pessoas o caráter anônimo de sua participação, que, após aceitarem participar da pesquisa de forma voluntária, assinaram ou gravaram em áudio o Termo de Consentimento Livre e Esclarecido (TCLE) e o Termo de Assentimento Informado Livre e Esclarecido (TAILE).
A amostra constituiu-se por conveniência totalizando seis adolescentes e seis cuidadores, identificados pela letra $\mathrm{A}$ e um número, e pela letra $\mathrm{C}$ e um número, respectivamente.

Como instrumentos de coleta de dados foram utilizadas duas entrevistas semi-estruturadas, uma direcionada aos adolescentes e outra aos cuidadores. Cada entrevista continha seis questões que abordavam o entendimento sobre os termos autonomia e independência; as vivências de autonomia e independência no cotidiano dos adolescentes; e a percepção do desempenho autônomo e independente dos adolescentes.

Cabe esclarecer que, após a aplicação das duas perguntas sobre o entendimento de autonomia e independência e antes das perguntas sobre as vivências cotidianas e percepções sobre o desempenho, foram explicados os termos adotados neste estudo, a fim de obter respostas que seguissem o mesmo parâmetro conceitual quanto às vivências autônomo-independentes dos adolescentes.

As entrevistas foram realizadas pelas pesquisadoras no período de fevereiro a maio de 2015 , nas dependências da instituição parceira do projeto. Todas as entrevistas foram áudio gravadas e transcritas para a realização da análise dos dados obtidos.

A análise de dados foi embasada pela Análise Hermenêutico-Dialética, que possibilita refletir, interpretar e explicar os discursos e correlacioná-los com o contexto em que a população pesquisada está inserida ${ }^{21}$. Permitindo para este estudo não apenas classificar e apontar os resultados obtidos quanto aos objetivos propostos, mas correlaciona-los com as experiências das pessoas com deficiência visual.

\section{RESULTADOS}

Participaram da pesquisa doze pessoas, sendo seis adolescentes com deficiência visual, três deles com cegueira (A1, A2 e A3) e três com baixa visão (A4, A5 e A6), com idades entre 14 e 17 anos, sendo apenas A1 do sexo masculino. E seis cuidadoras, todas mães dos adolescentes.

Os resultados são apresentados seguindo três eixos principais de análise: entendimento dos termos autonomia e independência; percepção do desempenho autônomo e independente nas atividades cotidianas; e fatores limitantes ou facilitadores para o desempenho autônomo e independente. Apesar deste último eixo não estar explicito no instrumento de coleta de dados, considerou-se relevante sua inclusão por ter sido mencionado no decorrer dos discursos das cuidadoras entrevistadas. 
No primeiro eixo, quanto ao entendimento do termo autonomia por parte dos participantes, alguns os definiram como sinônimo de independência, conforme apresentado abaixo:

Autonomia é quando a pessoa consegue se virar sozinha. (C4, 30 anos)

[...] eu acho que é uma coisa boa porque às vezes a gente tem que [...] ter independência nas coisas. (A1, 16 anos)

Em seguida, quando os participantes foram questionados sobre o termo independência, alguns também o definiram como sinônimo de autonomia:

É quando a pessoa tem autonomia, é poder fazer as coisas de uma forma mais liberal, independente. (C4, 30 anos)

A questão de ganhar autonomia. [...] Isso é uma independência. (A2, 17 anos)

Outros participantes demonstraram desconhecimento sobre os dois termos ou não conseguiram responder, por exemplo:

Eu não sei te responder esse. (C3, 32 anos)

O que que eu entendo por independência? [...] Não sei. Autonomia? É que a pessoa é muito ocupada, assim, autônoma... (A6, 14 anos)

Ainda, alguns participantes demonstraram ter conhecimento sobre a conceituação dos temos:

Pra mim independência, é uma pessoa que consegue fazer a maioria das coisas sem precisar, tipo, depender de algo ou de alguém pra fazer isso.

Quando a pessoa, [...] ela tem, tipo, voz sobre ela mesmo, quando alguém não fica falando por ela. Ela fala por ela mesma. (A4, 14 anos)

Independência? Independência é algo assim que a pessoa pode estar fazendo as coisas mais sozinho. Autonomia? Autorização de eu mesmo [...] Ter autoridade para fazer alguma coisa. (C5, 38 anos)

Referente ao segundo eixo de análise (percepção do desempenho autônomo e independente), depois de realizada a explicação dos conceitos de independência e autonomia, foi questionado aos participantes se os adolescentes realizam as atividades do dia a dia com independência, sendo que as respostas de todos foram positivas, porém, metade dos adolescentes apresentou alguma ressalva.

As ressalvas referidas foram quanto às atividades de locomoção. Sendo expostas por duas adolescentes suas dificuldades em andarem sozinhas e utilizarem transporte público:

Eu ainda não ando sozinha. É, assim, em questão de pegar um ônibus pra ir de um lugar pro outro não. (A2, 17 anos)

O que eu não consigo fazer é tipo andar, depender de onibus, transporte, essas coisas. (A5, 16 anos)

Além disso, uma das adolescentes afirmou que a única atividade que não realiza com independência é a de cozinhar.

Quando questionado se os adolescentes realizam as atividades do dia a dia com autonomia, as respostas foram, também, todas positivas, com ressalvas apresentadas, desta vez, por duas adolescentes e uma cuidadora. Todas as ressalvas nesta questão foram referentes ao papel dos pais, no sentido de estes serem os responsáveis por seus filhos até a idade adulta, como observado nas falas:

Porque tem aquele negócio: 'mãe, posso sair? Não, não pode’. Tem esses negócios de mãe. (A5, 16 anos)

As que eu posso, né?! Porque é a minha mãe quem manda em mim (risos). (A4, 14 anos)

Geralmente eu tento deixar ela decidir, [...] se é alguma coisa que eu vejo que não é legal, [...] dai eu já dou conselho pra ela: 'não, desista que isso dai não vai dar certo'. Ai ela acaba indo pela minha cabeça,né, e desiste, mas, fora isso, tranquilo. (C2, 37 anos)

A partir das respostas dos questionamentos anteriores, quanto às atividades desempenhadas pelos adolescentes com autonomia e independência, obtevese que todos os adolescentes, apesar de alguns com ressalvas, consideram-se autônomos e independentes, assim como todas as cuidadoras consideram seus filhos.

O terceiro eixo de análise refere-se a fatores limitantes e facilitadores para as vivências autônomoindependentes que surgiram durante as entrevistas. Neste sentido, é possível inferir que as cuidadoras identificam a deficiência visual enquanto limitação para a aquisição de funções, como explicitado nas falas a seguir. 
Eu acho que ela tem uma limitação, mas, ela não deixa de fazer o que as outras pessoas com... é... que têm menos limitações fisicas conseguem fazer. Ela faz tudo de forma com limitações. Digamos assim que, lógico, dentro do limite, mas não deixa de fazer as atividades que todo mundo faz. (C4, 30 anos)

Por isso que eu falo, a A6 com deficiência, ela ganha de quem enxerga. Entendeu?! Porque a força de vontade que ela tem é diferente totalmente de quem enxerga e não tem. Entendeu?! (C6, 31 anos)

Estes relatos possibilitaram identificar que as vivências autônomas e independentes dos adolescentes foram construídas com base no entendimento das implicações da deficiência visual no processo de aquisição de funções e na compreensão da importância da parceria neste processo, a não adoção de postura superprotetora.

Ah, acho que os pais, né?! Que dá essa autonomia pra ela, se os pais não dessem essa autonomia pra ela, né, tinha a gente que ficar decidindo o que ela ia fazer e o que não ia fazer. Acho que é isso. (C2, 37 anos)

Eu nunca fui assim, ou tento não ser, uma mãe que passa muito a mão na cabeça, né, ou que tenta fazer tudo, porque dai eu acho que eu fazendo isso, ela não se torna uma pessoa autônoma, e com o tempo é necessário ela desenvolver essa autonomia, porque não vai ter sempre as pessoas pra fazer as coisas pra ela. Ela vai ter que ter independência e autonomia também, né. Então, é importante que ela crie esse senso de responsabilidade, de compromisso e passe a gerir o tempo e as responsabilidades dela mesmo, né, no dia a dia. (C4, 30 anos)

Ela deixa. Ela fala: se não quiser fazer isso, então não faça! Ela não me obriga, sabe? [...] Acho que a maioria da minha vida eu decido por mim. Ela fala 'ó, você quer fazer, eu não vou te obrigar', ela sempre falou, desde o começo da minha vida, desde pequeno. (A1, 16 anos)

Contudo, as cuidadoras relataram, ainda, sobre o desconhecimento da sociedade quanto às especificidades e potencialidades da pessoa com deficiência visual e apontaram o instituto especializado enquanto promotor do desenvolvimento de habilidades dos seus filhos.

[...] falaram pra mim que eu não podia ter mais filho, que eu ia ter que cuidar só dela, né, 'nossa como é que você vai fazer com essa menina?', né, 'como é que você vai criar', né, 'não enxerga, como é que você vai fazer', né, e foi totalmente diferente. Mas pela idade que ela ta ela já faz bastante coisa sozinha, né?! Quem vê ela acha que não poderia fazer e ela faz, várias coisas, pelo menos ela é bem... fazer as coisas sozinha ela faz, pelo menos ela tenta fazer. (C2, 37 anos)

[...] Porque eu acho que, assim, quando ela começou aqui, ela não sabia botar calça, como eu falei pra você, ela não sabia colocar jaqueta, ela não sabia colocar no cabide, ela não sabia nada. Então ela chegou crua aqui, assim, tudo aqui ela aprendeu. E a gente foi ajudando ela em casa [...]. (C6, 31 anos)

\section{DISCUSSÃO}

Os resultados deste estudo apontam que, assim como a teoria aborda de maneiras distintas as definições dos termos autonomia e independência ${ }^{15,16,19}$, o entendimento referente a estes termos por parte dos participantes da pesquisa também varia: termos como sinônimos ( $C 4$, $A 1$ e A2), desconhecimento dos conceitos (C3 e $A 6)$ e discernimento do significado dos termos ( $A 4$ e $C 5$ ).

Todos os participantes do estudo apontaram que os adolescentes desempenham suas atividades cotidianas com independência e autonomia corroborando com o estudo realizado por Moura e Pedro ${ }^{22}$, no qual adolescentes com deficiência visual apontaram liberdade e autonomia como duas das principais mudanças que estavam experenciando nessa fase da vida.

Ainda com relação à percepção quanto às vivências de autonomia e independência alguns participantes ( $A 4$, $A 5$, e $C 2$ ) apresentaram ressalvas, exemplificando que, ao mesmo tempo em que os adolescentes desejam ser autônomos, relatam a necessidade de pedir permissão aos pais. Ao encontro disto, a literatura ${ }^{8,22}$ apresenta que nesta fase da vida, há procura por espaço na sociedade, anseio por liberdade e autonomia, bem como tornar-se independente com relação aos seus pais.

No debate sobre esta temática, é ressaltada a superproteção familiar como fator que, para além do cuidado, interfere no processo de desenvolvimento da autonomia e independência da pessoa com deficiência visual, se constituindo como um fator limitante deste processo $^{8,14,23}$. Em contraponto, as cuidadoras entrevistadas relataram não adotar a postura superprotetora, como supracitado nas falas de $C 2$ e $C 4$.

Porém, entende-se que para que os adolescentes com deficiência visual alcancem sua autonomia e 
independência é relevante o apoio da família, pois, é na relação familiar que são propiciadas as condições para a construção de $\operatorname{si}^{12,24,25}$. Este apoio foi demonstrado por todas as cuidadoras que participaram deste estudo, sendo apontada a parceria dos pais na fala do adolescente A1, que cita sua mãe como principal apoiadora de seu processo de aquisição de autonomia e independência.

Em contrapartida, $C 2$ expressou sobre como a visão socialdistorcidadapessoacomdeficiênciavisual podeimplicar em menosprezo e/ou desvalorização de suas capacidades. Esta mesma fala remete, ainda, ao desconhecimento popular sobre a deficiência, o que pode acarretar em julgamentos precipitados e opressão às famílias. Neste sentido, a literatura aborda que o papel de apoio não se restringe a família, pois a conscientização da sociedade em geral é essencial para que a pessoa com deficiência visual desenvolva suas capacidades e conquiste sua autonomia ${ }^{12,22,26,27}$.

Não obstante, $C 6$ acrescenta que o desenvolvimento de algumas habilidades ocorre no ambiente institucional, no qual atendimentos especializados e apoio escolar são realizados, favorecendo a população que frequenta. As diversas instituições são referenciadas como promotores de autonomia/independência para a população com deficiência visual, visto que, nesses contextos, são estabelecidas atividades e relações que auxiliam a potencialização de capacidades para alcançar seus objetivos e que permitem sustentar expectativas sobre o futuro ${ }^{14,26}$.

Os resultados deste estudo demonstraram grande aproximação da teoria com a prática, ao passo que os entrevistados abordaram aspectos condizentes com os encontrados na literatura disponível.

\section{CONCLUSÃO}

A partir da análise dos dados deste estudo, verificouse que os objetivos propostos foram atingidos, podendo- -se, assim, determinar que a compreensão dos termos autonomia e independência dos participantes deste estudo mostrou-se limitada, conforme a conceituação empregada nesta pesquisa.

A explicação dos termos como conceituados neste estudo permitiu um critério para a reflexão quanto às vivências dos adolescentes com deficiência visual. Assim, identificou-se que neste estudo não existiram discrepâncias entre as percepções dos adolescentes com deficiência visual e a de seus cuidadores quanto às vivências autônomo e independentes dos adolescentes, sendo que todos os participantes afirmaram que os adolescentes são autônomos e independentes.

Foi possível identificar, entender e aprofundar a discussão acerca da falta de clareza quanto aos conceitos de autonomia e independência, identificada tanto na amostra deste estudo quanto no referencial teórico próprio da Terapia Ocupacional, salientando que buscar a autonomia e independência das pessoas constitui-se, muitas vezes, como eixo norteador para este campo de conhecimento. Assim, aponta-se como fator limitante a escassez de publicações inerentes à área que definam estes termos.

Não obstante, os resultados demonstraram que a família possui papel fundamental no processo de desenvolvimento da pessoa com deficiência visual, podendo influenciar positiva ou negativamente. Ainda, indicaram a necessidade de conscientização social quanto às potencialidades desta população.

Por fim, ressalta-se necessidade de maior aprofundamento na temática desta pesquisa, considerando a discussão de temas pertinentes à Terapia Ocupacional e à pessoa com deficiência visual, como autonomia e independência. Contudo, aponta-se a relevância da realização de mais estudos que abordem a conceituação destes termos por profissionais da área e a compreensão da autonomia e independência de pessoas com deficiência visual.

AGRADECIMENTOS: As autoras agradecem às instituições parceiras do projeto e aos adolescentes e cuidadores que aceitaram participar voluntariamente da pesquisa. 


\section{REFERÊNCIAS}

1. Moraes M, Arendt RJJ. Aqui eu sou cego, lá eu sou vidente: modos de ordenar eficiência e deficiência visual. Cad CRH. 2011;24(6):109-120. Disponível em:. http:// dx.doi.org/10.1590/S0103-49792011000100008.

2. Malta J, Endriss D, Rached S, Moura T, Ventura L. Desempenho funcional de crianças com deficiência visual, atendidas no Departamento de Estimulação Visual da Fundação Altino Ventura. Arq Bras Oftalmol. 2006; 69 (4): 571-4. Disponível em: http://www.scielo.br/pdf/abo/ v69n4/31582.pdf.

3. Colenbrander A. Assessment of functional vision and its rehabilitation. Acta Ophthalmol. 2010;88:161-173(2). Disponível em: http://www.icoph.org/dynamic/attachments/ resources/functional_vision_report_-_2010.pdf.

4. Amiralian MLTM. Sou cego ou enxergo?As questões da baixa visão. Educar. 2004;(23):15-28. Disponível em: http://www.rc.unesp.br/igce/ceapla/cartografiatatil/artigos/ cego_enxergo.pdf.

5. Gasparetto MERF, Nobre MIRS. Avaliação do funcionamento da visão residual: educação e reabilitação. In: Masini EFS, organizador. A pessoa com deficiência visual: um livro para educadores. São Paulo: Vetor; 2007. p. 39-59.

6. Brasil. Ministério da Saúde. Secretaria de Atenção à Saúde. Área do adolescente e do jovem. Marco legal: saúde, um direito de adolescente. Brasília: Editora do Ministério da Saúde; 2007. Disponível em: http://bvsms.saude.gov.br/bvs/ publicacoes/07_0400_M.pdf.

7. Brasil. Ministério da Saúde. Lei nº 8.069, de 13 de julho de 1990. Dispõe sobre o Estatuto da Criança e do Adolescente e dá outras providências. Brasília; 1990. Disponível em: http://www.planalto.gov.br/ccivil_03/leis/18069.htm.

8. Amiralian MLTM. A deficiência redescoberta: a orientação de pais de crianças com deficiência visual. Rev Psicopedagogia. 2003;20(62):107-15. Disponível em: http://pepsic.bvsalud. org/pdf/psicoped/v20n62/v20n62a03.pdf.

9. Carvalho E NS. O adolescente com deficiência múltipla. In: Brasil. Ministério da Educação. Secretária de Educação Especial. Programa de capacitação de recursos humanos do ensino fundamental: deficiência múltipla. Brasília; 2000. p.82-111. Disponível em: http://portal.mec.gov.br/seesp/ arquivos/pdf/def_multipla_2.pdf.

10. Ormelezi EM. Aspectos psicossociais da baixa visão na adolescência. In: Sampaio MW, Haddad MAO, Filho HAC, Siaulys MOC. Baixa visão e cegueira: os caminhos para a reabilitação, a educação e a inclusão. Rio de Janeiro: Cultura Médica/Guanabara Koogan; 2010. p. 373-87.
11. Bezerra CP, Pagliuca LMF. A vivência da sexualidade por adolescentes portadoras de deficiência visual. Rev Esc Enferm USP. 2010;44(3):578-583. Disponível em: http:// www.scielo.br/pdf/reeusp/v44n3/05.pdf.

12. Chacon MCM, Defendi EL, Felippe MCGC. A família como parceira no processo de desenvolvimento e educação do deficiente visual. In: Masini EFS, organizador. A pessoa com deficiência visual: um livro para educadores. São Paulo: Vetor; 2007. p.130-74.

13. Senna SRCM, Dessen M A. Contribuições das teorias do desenvolvimento humano para a concepção contemporânea da adolescência. Psic Teor e Pesq. 2012; 28(1):101-8. Disponível em: http://www.scielo.br/pdf/ptp/v28n1/13.pdf.

14. Castilho CN, Contijo DT, Alves HC, Souza ACA. A gente tenta mostrar e o povo não vê: análise da participação de pessoas com cegueira congênita nos diferentes ciclos da vida. Cad Ter Ocup UFSCar. 2011;19(2):189-281. Disponível em: http://www.cadernosdeterapiaocupacional. ufscar.br/index. php/cadernos/article/view/461/326.

15. Houaiss A. Minidicionário Houaiss da língua portuguesa. 2a ed. rev. aum. Rio de Janeiro: Objetiva; 2009.

16. Campos, RTO, Campos GWS. Co-construção de autonomia: o sujeito em questão. In: Campos GWS, Minayo MCS, Akerman M, Junior MD, Carvalho YM, organizadores. Tratado de saúde coletiva. São Paulo: Hucitec; 2006. p.69-714.

17. Riberto $M$, tradutor. Orientação funcional para a utilização da MIF. São Paulo: Hospital de Clínicas da Faculdade de Medicina da Universidade Estadual de São Paulo. s/a.

18. Baptiste S. Enabling communication in a person-centred, occupation-focussed context. In: Curtin M, Molineux M, Supyk J. Occupational Therapy and Physical Dysfunction: Enabling Occupation. $6^{\mathrm{a}}$ ed. New York : Churchill Livingstone/Elsevier, 2010. p. 151-160.

19. Hammel J, Charlton J, Jones R, Kramer JM, Wilson t. Dos direitos da incapacidade à conscientização esclarecida.. In: Crepeau EB, Cohn ES, Schell BAB. Williard \& Spackman Terapia Ocupacional. 11a ed. Rio de Janeiro: Guanabara Koogan; 2011. p. 880-900.

20. Silva A A. Prática clínica baseada em evidências na área da saúde. São Paulo: Editora Santos; 2009.

21. Minayo MCS. O desafio do conhecimento: pesquisa qualitativa em saúde. 7a ed. São Paulo: Hucitec; 2000.

22. Moura GR, Pedro ENR. Adolescentes portadores de deficiência visual: percepções sobre sexualidade. Rev Latino-Am Enfermagem. 2006; 14(2):220-226. Disponível em: http://www.scielo.br/pdf/rlae/v14n2/v14n2a11.pdf. 
23. Corrêa GC, Santana VC. Avaliação do impacto de uma intervenção de terapia ocupacional com ênfase no desempenho ocupacional de crianças e adolescentes com deficiência visual. Rev Ter Ocup Univ São Paulo. 2014; 25(1):43-50. doi: http://dx.doi.org/10.11606/issn.2238-6149. v25i1p43-50.

24. Silva MR, Airoldi MJ. A influência do familiar na aquisição de habilidades funcionais da criança com deficiência visual. Rev Ter Ocup Univ São Paulo. 2014; 25(1):36-42. doi: http://dx.doi.org/10.11606/issn.22386149.v25i1p36-42.

25. Krameck K, Nascimento GCC. A orientação à família de pessoas com deficiência. Rev Ter Ocup Univ São Paulo.
2015;26(1):128-35. doi: http://dx.doi.org/10.11606/ issn.2238-6149.v26ilp128-135.

26. Aciem TM, Mazzotta MJS. Autonomia pessoal e social de pessoas com deficiência visual após reabilitação. Rev Bras Oftalmol. 2013;72(4):261-267. Disponível em: http://www.scielo.br/scielo.php?pid=S003472802013000400011\&script=sci_arttext.

27. Bittencourt ZZLC, Hoehne EL. Qualidade de vida de deficientes visuais. Medicina (Ribeirão Preto). 2006; 39(2):260-264. doi:http://dx.doi.org/10.11606/issn.21767262.v39i2p260-264.

Recebido em: 21.09.15

Aceito em: 21.03.16 